Abstracta Iranica Iranica

Revue bibliographique pour le domaine irano-aryen

Volume 34-35-36 | 2017

Comptes rendus des publications de 2011-2013

\title{
Lisa Balabanlilar. Imperial Identity in the Mughal Empire. Memory and Dynastic Politics in Early Modern South and Central Asia
}

\section{Denise Aigle}

\section{(2) OpenEdition \\ Journals}

Édition électronique

URL : http://journals.openedition.org/abstractairanica/41824

DOI : 10.4000/abstractairanica.41824

ISSN : 1961-960X

Éditeur :

CNRS (UMR 7528 Mondes iraniens et indiens), Éditions de l'IFRI

Référence électronique

Denise Aigle, «Lisa Balabanlilar. Imperial Identity in the Mughal Empire. Memory and Dynastic Politics in Early Modern South and Central Asia », Abstracta Iranica [En ligne], Volume 34-35-36 | 2017, document 10, mis en ligne le 30 décembre 2016, consulté le 28 septembre 2020. URL : http:// journals.openedition.org/abstractairanica/41824; DOI : https://doi.org/10.4000/abstractairanica. 41824

Ce document a été généré automatiquement le 28 septembre 2020.

Tous droits réservés 


\title{
Lisa Balabanlilar. Imperial Identity in the Mughal Empire. Memory and Dynastic Politics in Early Modern South and Central Asia
}

\author{
Denise Aigle
}

\section{RÉFÉRENCE}

Lisa Balabanlilar. Imperial Identity in the Mughal Empire. Memory and Dynastic Politics in Early Modern South and Central Asia. London, Tauris, 2012, xix + 216 p., illustrations, maps. ISBN : 978-1848857261

Cette étude, fondée sur un grand nombre de sources en persan, turc chaghatai et arabe (p. 192-198), montre comment les héritages turko-mongols ont fini par devenir des marqueurs d'identité. L'ouvrage est composé d'un prologue, suivi de quatre chapitres et d'une conclusion. Dans le prologue (« Timurid Political Charisma and the Ideology of Rule », p. 7-17), l'A. décrit les cadres idéologiques timourides, ancrés dans l'héritage de Gengis Khan. Tamerlan apporta à l'idéologie de la conquête gengiskhanide des éléments complémentaires : importance du leadership charismatique, notamment avec le titre de "Lord of the auspicious conjonction » (șāhib-qirān), l'islam comme outil de légitimation, développement de la culture littéraire persane et aménagement de jardins d'agrément (p. 12-13). Ces éléments seront repris plus tard par les empereurs moghols. Dans les deux premiers chapitres («Babur and the Timurid Exile », p. 18-36, et « Dynastic Memory and the Genealogical Cult », p. 37-70), l'A. s'intéresse à l'identité moghole dans le cadre du concept de «memoria » en analysant tout particulièrement le Bābur-nāma. Elle étudie les conditions particulières de l'arrivée de Bābur en Inde, montrant que cet événement, vécu comme un " exil », eut un impact sur la manière dont les Moghols se sont constitués en une dynastie conquérante (p. 27-28). L'expérience de la migration a façonné la manière dont les lignages moghols furent 
manipulés pour être adaptés à des besoins historiques différents. Les ouvrages généalogiques (silsila-nāma), produits dans les scriptoria moghols, témoignent de la volonté des souverains de se donner une légitimité ancrée dans la lignée impériale mongole à travers Tamerlan. Les chapitres 3 (« The Peripatetic Court and the TimuridMughul Landscape », p. 71-99) et 4 (" Legitimacy, Restless Princes and the Imperial Succession », p. 100-139) traitent de thèmes familiers aux spécialistes de l'Iran, de l'Asie centrale et de l'Inde, tels l'architecture, les jardins et la chasse royale, que l'A. examine dans le cadre de la formation de l'identité moghole. Comme les Timourides, les Moghols ont manifesté leur pouvoir impérial à travers des projets architecturaux, dont les villes de Fatḥpūr Sīkrī et Šāhğahānābād sont les plus célèbres. Cependant, aucune ville ne resta longtemps un centre impérial, car la mobilité demeurait un trait de la culture de cour : un camp royal mobile ( $u r d u$ ), sur le modèle centrasiatique, servit de capitale jusqu'au XVIII ${ }^{e}$ s. (p. 72). L. Balabanlilar utilise non seulement une grande variété de sources primaires, mais elle met aussi en œuvre des concepts théoriques (mémoire, exil, migration, identité, imagination) qui sont très utiles à l'analyse. Cette approche originale met en lumière l'héritage timouride de la dynastie moghole, ce qui, jusqu'ici, n'avait pas été suffisamment souligné.

\section{AUTEURS}

\section{DENISE AIGLE}

CNRS-UMR 8167 « Orient et Méditerranée » 